\title{
Development of a Multifunctional All-Terrain Vehicle Equipped with Intelligent Wheel-Drive System for Providing Increased Level of Energy Efficiency and Improved Fuel Economy
}

\author{
V.V. Belyakov, P.O. Beresnev, D.V. Zeziulin, A.A. Kurkin, \\ V.S. Makarov and V.I. Filatov
}

\begin{abstract}
The use of hydrostatic transmission driveline as a part of multi-wheeled all-terrain vehicles on ultralow pressure tires allows achieving the efficient power distribution for driving wheels depending on the conditions of vehicle-terrain interaction. This provides a significant increase in average speeds of vehicle movement in difficult road conditions (the maximum possible traction force is implemented by automatic maintaining the required level of wheel slip). At the same time, the minimum energy losses of wheel-soil interaction (improved fuel economy) and environmental safety of wheels, when operating on soft soil and vegetation, are provided. Installing the hydrostatic transmission allows to optimize layout scheme at the expense of the free selection of placement of transmission units. Application of integrated combination of active drive wheels, tires ultralow pressure, independent suspension system, the ability to control all the wheels according to any given algorithm (ability to control turning by all wheels) when
\end{abstract}

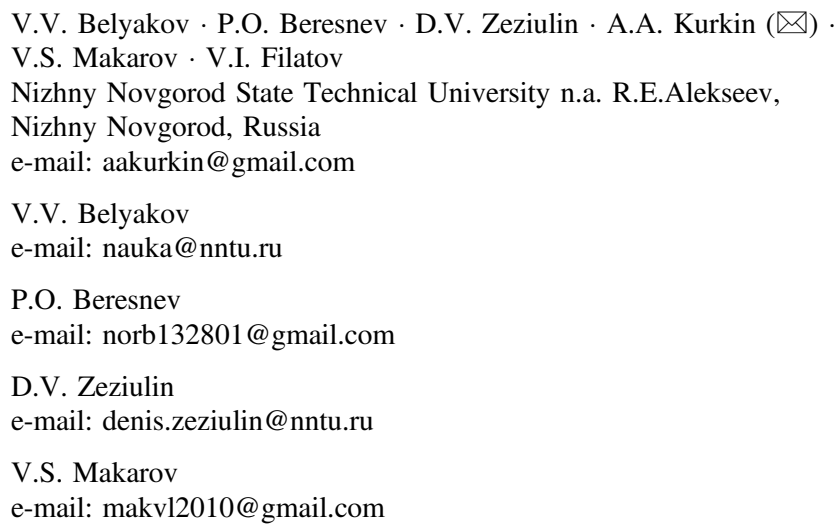


driving on soft soil allows to effectively carry out the transportation operation with preservation of the ecology of the soil cover.

Keywords Multifunctional all-terrain vehicle $\cdot$ Hydrostatic transmission driveline Efficiency $\cdot$ Fuel consumption

\section{Introduction}

In the market of modern all-terrain vehicles (ATV) there has been formed quite developed segment of vehicles on ultralow pressure tires. The maximum ground pressure of these vehicles is much lower than that of known types of wheeled and tracked vehicles. Furthermore, the method of rotation at the expense of steered wheels makes the minimal detrimental impact on the soil and makes possible the preservation of soil and vegetation cover even when turning with a small radius.

It should be emphasized that the ATV tires on ultralow pressure tires with wheel arrangement $8 \times 8$ are inherently potential competitors of tracked vehicles. They exert significantly less harmful impact on the soil cover, while providing a similar carrying capacity. The most well-known vehicles are the following: Shaman [1], Tundra [2], Trom [3], Xpen [4], Staratel [5], Strannik [6].

However, for movement on difficult terrain in case of sudden change in traffic conditions to ensure the efficiency of vehicle functioning is only possible by timely alterations of basic operation modes of separate units and systems of the vehicle, then most of the models in this class of ATV do not possess.

The current trend of ATV developers around the world is the development of intelligent control systems, capable of providing pre-emptive response effect on the various situations, which arise while driving, and significantly improving the performance characteristics of vehicles by introducing so-called adaptive mobility (agility).

By present time in studies as the most effective means of improving the mobility and efficiency of vehicles there is noted the use of «flexible intelligent» transmissions, which can be implemented on the basis of electromechanical or hydrostatic drives [7, p. 17].

«Intelligent» driveline provides an adjustable vehicle behavior, in particular, the multi-axle vehicle, operating in off-road conditions. The advantage of this transmission is in the ability to provide fast and accurate response to changes in force and kinematic parameters of motion. The best object of automatic control systems among all currently existing types of continuously variable transmission is the hydrostatic transmission because of the very low inertia and high «rigidity» of drive [8, p. $182 ; 9$, p. 17] 


\section{Development of the Multifunctional All-Terrain Vehicle}

The purpose of the project is obtainment of significant scientific and technological results, which help to start creating high-performance multifunctional all-terrain vehicles (MATV), equipped with intelligent wheel-drive system for providing increased level of energy efficiency and improved fuel economy.

The purpose requires solving the following tasks:

1. Analysis of the layout schemes and designs of $8 \times 8$ vehicles and the existing power distribution strategies for driving wheels;

2. Development of mathematical model of MATV movement in off-road conditions and conducting simulation with the definition of rational parameters and obtaining initial data for designing;

3. Development of mathematical model of intelligent wheel-drive system functioning and control algorithms, identification of settings of the hydrostatic transmission, ensuring the achievement of the required energy efficiency on terrain;

4. Development of design documentation, manufacturing of an experimental prototype of MATV with subsequent adaptation of control laws of the wheel-drive system;

5. Conducting research tests of the experimental prototype under different operating conditions, and identifying ways to improve the design.

The use of hydrostatic transmissions combining individually regulated power actuator of each wheel with automatic control system allows achieving the efficient torque distribution for driving wheels depending on the conditions of vehicle-terrain interaction. The best-known vehicle with the hydrostatic transmission is three-axle vehicle "Gidrohod-49061», designed by the Central research and development automobile and engine institute «NAMI». From the results of evaluating demand for the generated MATV it must be concluded that competitive vehicle must relate to a lesser weight category [10, p. 947; 11, p. 517], have independent suspension, the control system of all wheels turning and ultralow pressure tires.

Selection of rational parameters of the MATV and obtaining initial data for designing was carried out according to the results of simulation modeling of the MATV motion in off-road conditions and analysis of statistical dependencies between power characteristics, capacity, average ground pressure and total mass of vehicles of this class [12, p. 4].

When selecting chassis parameters there was used optimization method based on the choice of design parameters contributing to ensure the minimum energy consumption for MATV moving on terrain. The installation of hydrostatic transmission driveline ensures the optimal arrangement of vehicle aggregates (due to more the free choice of placement of transmission units).

The most well-known strategies of power distribution for driving wheels of multiaxial vehicles, including vehicles with electro-mechanical systems and 
hydrostatic transmission, were analyzed by authors in [13, p. 123; 14, p. 159]. Restrictions in the issue of their technical realization were identified.

The studies have revealed that the most effective scheme for the MATV is hydro-differential wheel-drive of sides (Fig. 1). The ability to adjust the torque on the sides can improve throughput and influence maneuverability. There are possibilities of oversteering and skid steering, and there is no circulation of parasitic power between wheels of one side. Adjusting the torque on each of wheels based on readings of inertial navigation system, angular rate sensors and pressure sensors in hydraulic lines. The change of working volumes of hydraulic motors as required allows implementing maximum adhesion and minimal resistance to movement at each wheel when driving on typical soils of terrain.

Development, debugging, and evaluation of the efficiency of different algorithms of torque distribution in accordance with the condition of maximum traction force and minimum energy consumption for transportation were conducted using simulation model of MATV's wheel-drive system.

Parameters, characteristics, and adjustments of the hydrostatic transmission, ensuring achievement of the desired energy efficiency on terrain, were determined.

During carrying out virtual tests the following parameters of the MATV motion were determined: angular accelerations, slippage, and torque at the wheels; velocities and accelerations of MATV's center of mass; ground reaction forces

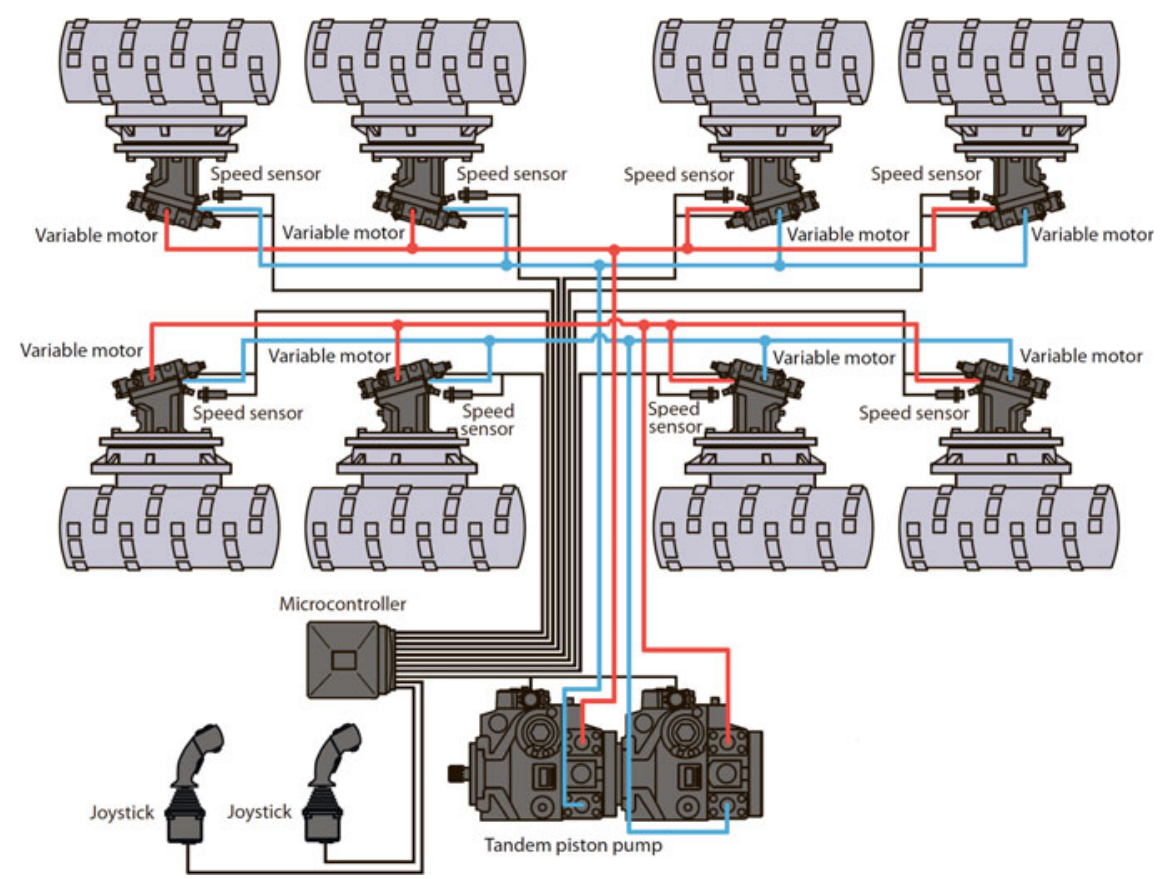

Fig. 1 Structural transmission scheme 
implemented by wheels. Realization of control of MATV motion in the simulation model was carried out by using PID-controller.

Parameters of hydraulic aggregates are calculated from the following expressions:

pump:

$$
T_{\mathrm{H}}=p_{w} q_{\mathrm{H}}\left(2 \pi \eta_{\mathcal{H}}\right)^{-1} ; Q_{\mathrm{H}}=q_{\mathrm{H}} \omega_{\mathrm{H}} \eta_{V_{\mathrm{H}}},
$$

motor:

$$
T_{\mathrm{M}}=p_{w} q_{\mathrm{M}} \eta_{\mathcal{M}}(2 \pi)^{-1} ; Q_{\mathrm{M}}=q_{\mathrm{M}} \omega_{\mathcal{M}} \eta_{V_{\mathrm{M}}}^{-1},
$$

where $T_{\mathrm{H}}, T_{\mathrm{M}}$-torques on the shaft of the pump and motor; $Q_{\mathrm{H}}, Q_{\mathrm{M}}$-maximum output of the pump and motor, respectively; $p_{w}$ - pressure-drop of the working fluid in lines of hydraulic machines; $q_{\mathrm{H}}, q_{\mathrm{M}}$-working volume of the pump and motor; $\eta_{V_{\mathrm{H}}}, \eta_{V_{\mathrm{M}}}$-volumetric efficiency of the pump and motor, respectively, $\omega_{\mathcal{H}}, \omega_{\mathcal{M}}$ angular velocities of the pump and motor.

The distribution of torque for shafts of motors approximately corresponds to the ratio of their working volumes $[15$, p. 336]:

$$
T_{\mathrm{M}_{1}}: T_{\mathrm{M}_{2}}: T_{\mathrm{M}_{3}}: \ldots: T_{\mathrm{M}_{\mathrm{n}}} \approx q_{\mathrm{M}_{1}}: q_{\mathrm{M}_{2}}: q_{\mathrm{M}_{3}} ; \ldots: q_{\mathrm{M}_{\mathrm{n}}} \text {. }
$$

Angular velocities of hydraulic motors are calculated from the dependence [15, p. 336]:

$$
Q_{\mathrm{H}} \approx q_{\mathrm{M}_{1}} \omega_{\mathcal{M}_{1}}+q_{\mathrm{M}_{2}} \omega_{\mathcal{M}_{2}}+q_{\mathrm{M}_{3}} \omega_{\mathcal{M}_{3}}+\ldots+q_{\mathrm{M}_{\mathrm{n}}} \omega_{\mathcal{M}_{n}}
$$

Applied to the drive wheel torque from the hydraulic pump is spent to overcome rolling resistance, wheel acceleration and the implementation of traction. The general equation of wheel dynamics has the form:

$$
I_{\mathrm{K}} \cdot \dot{\omega}_{\mathrm{K}}=T_{\mathrm{M}} i_{\mathrm{p} . \mathrm{M}} \eta_{\mathrm{p} . \mathrm{M}}-T_{\mathrm{co} \Pi \mathrm{p}},
$$

where $T_{\text {coПp }}$-drag torque of wheel rotation (load); $I_{\mathrm{K}}$-moment of inertia of the wheel, $\dot{\omega}_{\mathrm{K}}$ - angular acceleration of the wheel, $i_{\mathrm{p} . \mathrm{M}}$ - final drive gear ratio; $\eta_{\mathrm{p} . \mathrm{M}}$ efficiency of the final drive.

The torque of resistance to wheel rotation is determined by the rolling resistance of the wheel $T\left(R_{z}\right)$ and torque that is created by the tangential component of the force of wheel-soil interaction $T\left(R_{x}\right)$ :

$$
T_{\text {соПр }}=T\left(R_{z}\right)+T\left(R_{x}\right) .
$$

The model of work of the hydrostatic transmission driveline during the motion of a multiaxial vehicle is described in more detail in [16, p. 61]. 
To select rational options of the hydrostatic transmission control system the following algorithms were analyzed $[17$, p. $224 ; 18$, p. $79 ; 19$, p. 3; 20, p. 41]:

- individual slip control for wheels of a side with a certain linear velocity of the center of mass of MATV's chassis (with the iterative selection of the optimum value of slippage);

- torque control algorithm for wheels of a side based on the known minimum wheel angular velocity («high-threshold» control with limitation of the angular acceleration of the wheels);

- torque control algorithm based on the average wheel angular velocity of a side.

Virtual tests of MATV moving on the ground with the changing characteristics of resistance and adhesion are the most revealing, since they reflect the real character of the vehicle-terrain interaction. Examples of changes in the instantaneous fuel consumption in cases of using different algorithms are shown in Fig. 2.

According to the results of numerical modeling there was carried out an assessment of MATV energy efficiency and fuel economy, which allowed drawing conclusions about the effectiveness of the wheel-drive system control algorithms. When moving on " mixed » surface the developed control algorithms alongside with the radical increase of trafficability allow to increase the efficiency of the MATV movement up to $10 \%$ and reducing fuel consumption up to $18 \%$ depending on the selected regulation algorithm.

General views of 3D model and experimental prototype of produced MATV are presented in Fig. 3, and technical characteristics are given in Table 1. In making

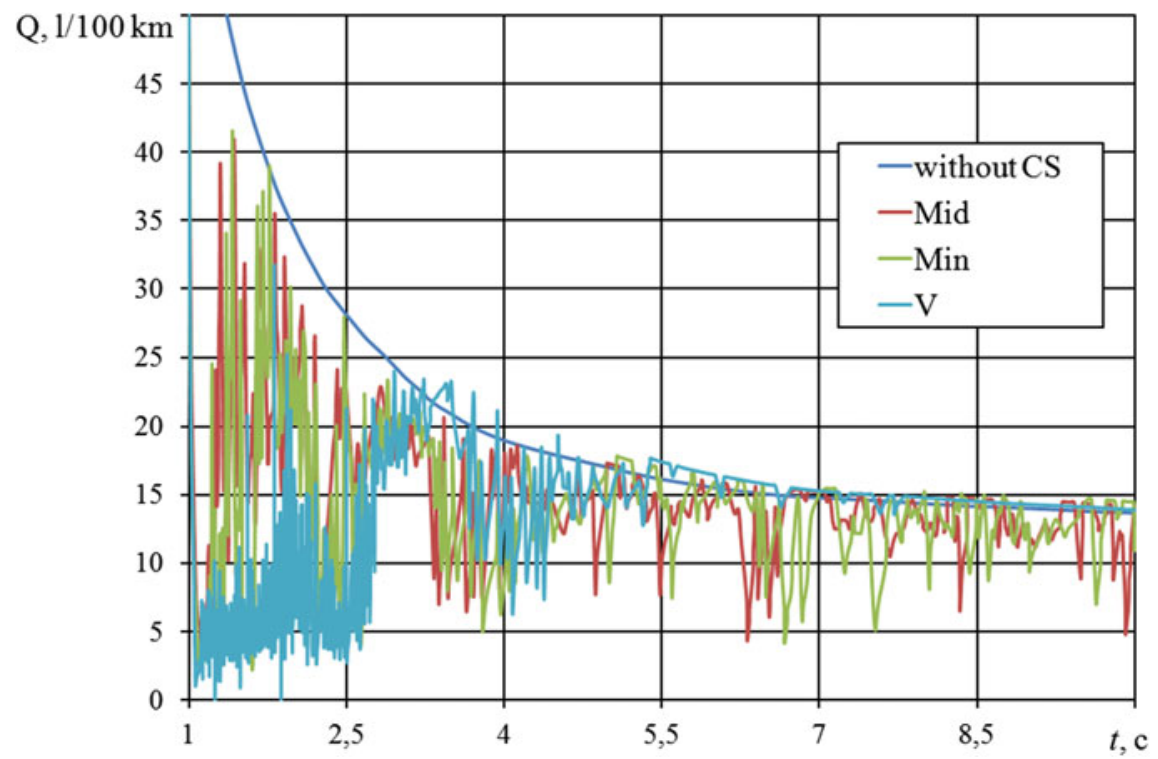

Fig. 2 Graphs of fuel consumption changes at various regulation laws: «without CS»—without control system, «Mid»-algorithm based on the average wheel angular velocity, «Min»—《High-threshold» control, «V»—-individual slip control 

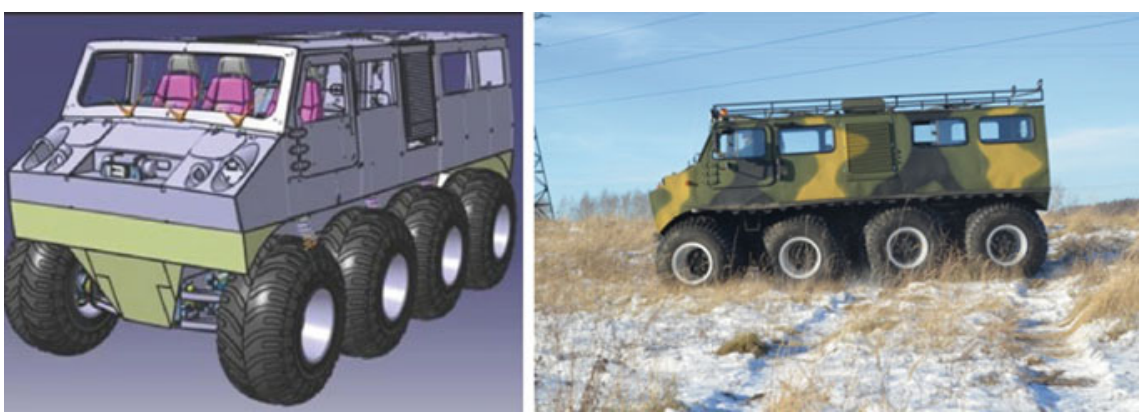

Fig. 3 General views of 3D model and experimental prototype of the produced MATV

Table 1 MATV technical characteristics

\begin{tabular}{|c|c|}
\hline Parameters & Characteristics \\
\hline Wheel arrangement & $8 \times 8$ \\
\hline $\begin{array}{l}\text { Number of seats (including the } \\
\text { driver) }\end{array}$ & 13 \\
\hline Body & amphibious (floating) \\
\hline Curb weight, kg & 4500 \\
\hline Cargo weight, kg & 3500 \\
\hline $\begin{array}{l}\text { Dimensional (overall) } \\
\text { length/width, mm }\end{array}$ & $5650 / 2800$ \\
\hline $\begin{array}{l}\text { Dimensional (overall) height, } \\
\mathrm{mm}\end{array}$ & 2800 \\
\hline Wheelbase, $\mathrm{mm}$ & 4350 \\
\hline Track width, mm & 2100 \\
\hline Ground clearance, $\mathrm{mm}$ & 550 \\
\hline Power, $\mathrm{kW}$ (hp) for rpm & $110(150)$ for 2400 \\
\hline Torque, $\mathrm{N} \cdot \mathrm{m}$ for $\mathrm{rpm}$ & 490 for $1500-1700$ \\
\hline Driveline & hydrostatic \\
\hline Hydraulic pumps & $\begin{array}{l}2 \text { axial piston pumps with adjustable volume. Working } \\
\text { volume of } 125 \mathrm{~cm}^{3}\end{array}$ \\
\hline Hydraulic motors & $\begin{array}{l}8 \text { axial piston motors with adjustable volume. } \\
\text { Working volume of } 107 \mathrm{~cm}^{3}\end{array}$ \\
\hline Steering System & Turning of each wheel/Skid steering system \\
\hline Suspension system & Independent suspension \\
\hline Tires & ultralow pressure tires (dimension $52,2 \times 25,5-24$ ) \\
\hline $\begin{array}{l}\text { Maximum speed on } \\
\text { highway/water, } \mathrm{km} / \mathrm{h}\end{array}$ & $60(5)$ \\
\hline Minimum turning radius, $\mathrm{m}$ & 15 \\
\hline Angle of ascent at full load, deg & 30 \\
\hline
\end{tabular}



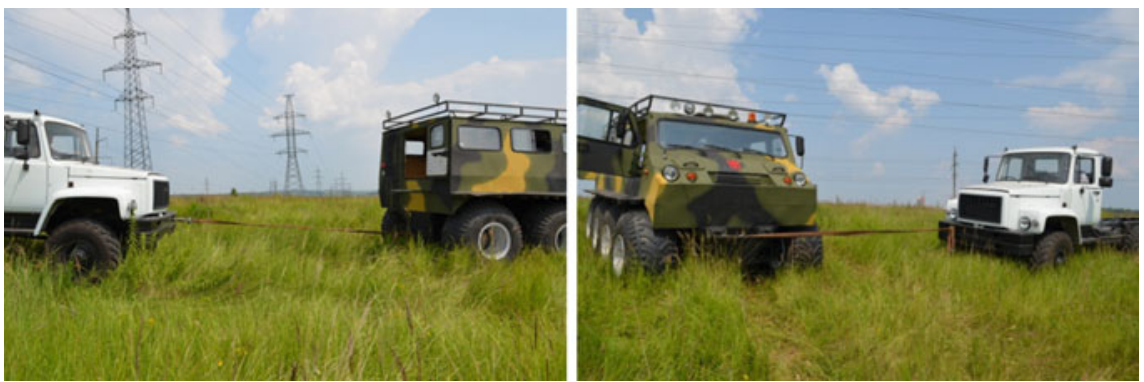

Fig. 4 Fragments of field trials

design and technological solutions the approach, that provides the highest unification of components and assemblies, as well as the use of parts, assemblies and units of domestic production in the MATV design, was used. [21, p. 41; 22, p. 24].

The central stage of the procedure for creating a workable technology is to conduct field tests of an experimental prototype (Fig. 4) to identify ways of the design optimization. Conducting experimental researches allowed to evaluate the efficiency of the MATV; reliability of operation in matters of trafficability, stability of motion, and maintain performance of its units in difficult climatic conditions; determine the values of parameters and indicators of performance properties of the designed chassis.

MATV has the ability to control all its wheels on any given algorithm and achieve rational angles of rotation of the wheels. This technical result is achieved by the fact that hydraulic cylinders for turning control are used in the MATV for each wheel (but not only one for each axle as in analogs).

\section{Conclusions}

The research results are technical solutions for creating high-performance multifunctional all-terrain vehicles on low pressure tires with hydrostatic transmission driveline and the possibility to control turning by all wheels.

Technical implementation of the proposed solutions was carried out taking into account the results of the analysis of layout schemes and designs of $8 \times 8$ ATV, as well as the existing power distribution strategies for driving wheels of multiaxial vehicles. Structural, functional and hydraulic circuits of the MATV have been developed.

Conducting simulation of the MATV movement with the intelligent wheel-drive system in off-road conditions has allowed to select rational parameters of the chassis, ensures the development and virtual testing of torque distribution laws for driving wheels according to conditions of their interaction with the terrain, providing minimum energy consumption for transportation. Forecasting MATV 
performance with hydrostatic transmission control system has been organized on the base of study of chassis dynamics when driving on the ground surface with variable characteristics.

Preliminary design has been developed and the MATV experimental prototype has been manufactured. Torque distribution algorithms for driving wheels, designed accompanying imitation modeling, have been adapted for hydrostatic drive control system of the MATV experimental prototype.

Research testing of the MATV experimental prototype has been carried out, specifications and values of operational properties indicators of the designed chassis have been determined. Finalization of the MATV prototype has been performed according to test results.

Acknowledgements Research are carried out with the financial support of the state represented by the Ministry of Education and Science of the Russian Federation. Agreement no. 14.574.21.0107 8.Sep 2014 Unique project Identifier: RFMEFI57414X0107

\section{References}

1. AVTOROS, All terrain vehicle $8 \times 8$ Shaman URL. http://avtoros.info/en/node/240. Accessed 16 May 2016

2. Group firms SKARN URL. http://www.skarn.ru. Accessed 29 April 2016

3. Off-road vehicles 8 x8 Trom URL. http://trom8x8.ru. Accessed 01 March 2016

4. All-Terrain Vehicle « Xpen » URL. http://xpen.komi-nao.ru/. Accessed 11 May 2016

5. All-terrain amphibious vehicles of Russia URL. http://вездеходы-амфибии.рф. Accessed 05 May 2016

6. All-Terrain Vehicle « Strannik » URL. http://atvstrannik.ru. Accessed 15 March 2016

7. Pliev, I.A.: Control algorithms of the power delivered to the wheels of four-wheel drive. J. Automotive Eng. 3(74), 16-18 (2012)

8. Gorelov, V.A.: Forecasting of the characteristics of the curvilinear motion of all-wheel-drive vehicle with the steering 1-0-3 at various laws of the control wheels of the rear axle: Cand. diss. p. 200. Moscow, MGTU im. N.E. Baumana, (2008)

9. Chizhov, D.A.: Development of complex techniques to improve energy-wheel drive wheeled vehicle: Cand. tehn. sci. diss. p. 146. Moscow (2012)

10. Belyakov, V., Kurkin, A., Makarov, V., Zeziulin, D.: Multifunctional vehicle for coastal areas. Proceedings of the 12th International Conference on the Mediterranean Coastal Environment, MEDCOAST. 2, 945-951 (2015)

11. Zeziulin, D., Makarov, V., Belyaev, A., Belyakov, V.: Development of multi-wheeled all-terrain vehicle with hydrostatic transmission driveline. In: 13th European Conference of the International Society for Terrain-Vehicle Systems, p. 517-523, Rome, Italy, 21-23 October 2015

12. Barakhtanov, L.V., Beliakov, V.V., Zeziulin, D.V., Makarov, V.S., Manianin, S.E., Tropin, S. L.: Substantiation of rational design of cross country transport vehicle with $8 \times 8$ axle arrangement. Russ. Eng. Res. 6, 3-5 (2015)

13. Serebrennyi, I.V.: Increased support cross-wheel drive vehicle through the rational distribution of power at the wheels. Cand. tech. sci. diss. p. 161. Moscow (2009)

14. Ushnurtsev, S.V., Keller, A.V., Usikov, V.Yu.: Control method for power distribution between driving wheels of car of universal purpose on mutual deviation of kinematic and power factors. Omsk Sci. Bull. 1-107 (107) (2012) 
15. Shukhman, S.B., Solov'ev, V.I., Prochko, E.I.: Theory of power drive all-terrain vehicles wheels. - M.: Agrobiznest-sentr publ., (2007). p. 336

16. Kurmaev, R.Kh.: Method of increasing the efficiency of all-wheel drive multi-axis machine with hydrostatic transmission through the use of corrective algorithms. Cand. tech. sci. diss. p. 229. Moscow (2009)

17. Lepeshkin, A.V.: Methods of creating an "intelligent" automatic adaptive transmission control multidrive wheeled vehicle. Izvestiya MGTU MAMI. 2012. V. 1. 2(14), 222-228

18. Gorelov, V.A., Maslennikov, L.A., Tropin, S.L.: Forecasting performance of curvilinear motion in multi wheeled vehicles for different all-wheel steering laws. Sci. Educ. Bauman MSTU. 5. Available at: http://technomag.edu.ru/doc/403845.html (2012), Accessed 10 April 2016

19. Gorelov, V.A., Kotiev, G.O., Miroshnichenko, A.V.: Synthesis of control traction motor for individual drive wheeled vehicle. Sci. Educ. Bauman MSTU. 12. Available at: http://www. technomag.edu.ru/en/doc/282533.html (2011), Accessed 20 Aug 2012

20. Gorelov, V.A., Kotiev, G.O., Miroshnichenko, A.V.: Individual drive control algorithm wheel propulsion vehicles. Herald of the Bauman Moscow State Technical University. Series Mechanical Engineering. Special issue Power and transport engineering. 2011. p. 39-58

21. Beliakov, V.V., Zeziulin, D.V., Makarov, V.S., Kurkin, A.A.: Development of a multi-axle all-terrain vehicle with hydrostatic transmission. Proceedings of Higher Educational Institutions. Machine Building. 10(679), 39-48 (2016)

22. Beliakov, V.V., Beresnev, P.O., Filatov, V.I., Shapkina, Yu.V.: Multifunctional vehicle for coastal zones. Ecol. Syst. Dev. 8, 23-28 (2016)

Open Access This chapter is licensed under the terms of the Creative Commons Attribution 4.0 International License (http://creativecommons.org/licenses/by/4.0/), which permits use, sharing, adaptation, distribution and reproduction in any medium or format, as long as you give appropriate credit to the original author(s) and the source, provide a link to the Creative Commons license and indicate if changes were made.

The images or other third party material in this chapter are included in the chapter's Creative Commons license, unless indicated otherwise in a credit line to the material. If material is not included in the chapter's Creative Commons license and your intended use is not permitted by statutory regulation or exceeds the permitted use, you will need to obtain permission directly from the copyright holder.

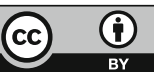

